\title{
FORMAÇÃO INICIAL DE PROFESSORES DE LÍNGUA INGLESA: O GLOCAL EM ARTICULAÇÕES ENTRE UNIVERSIDADE E ESCOLAS
}

\section{Preservice English teacher education: glocal knowledge in university and school interrelationships}

\author{
Rosinda de Castro Guerra RAMOS \\ Universidade Federal de São Paulo, (UNIFESP), Guarulhos, Brasil \\ Sueli Salles FIDALGO \\ Universidade Federal de São Paulo, (UNIFESP), Guarulhos, Brasil \\ Terezinha Maria SPRENGER \\ Universidade Federal de São Paulo, (UNIFESP), Guarulhos, Brasil
}

\begin{abstract}
RESUMO: No presente artigo, visamos a ilustrar como uma proposta de formação de professores busca integrar o conhecimento local globalizado e o conhecimento global localizado, conceito a que Kumaravadivelu(2006) se refere como glocal. Assim, centradas nesse objetivo, descrevemos o curso integrado de Licenciatura em PortuguêsInglês da Universidade Federal de São Paulo (Unifesp), enfocando especificamente a formação de professores de inglês, área em que atuamos. Primeiramente, fazemos uma exposição geral do curso em foco e de seus princípios teóricos que o alicerçam. A seguir, apresentamos as disciplinas especificas de língua e literaturas de língua inglesa para então destacarmos as que tratam especificamente da formação de professores de inglês. Finalmente analisamos excertos de relatórios de estágio para verificar o que revelam sobre a articulação entre o local e global.
\end{abstract}

PALAVRAS-CHAVE: Formação inicial; Professores de inglês; Conhecimentos Global; Conhecimento Local

\begin{abstract}
In this paper, we aim at illustrating how a teacher education program searches for the integration between globalized local knowledge and localized global knowledge, referred to as "glocal" by Kumaravadivelu (2006). Having this aim in mind, we describe the Portuguese-English Teacher Education Program at the Federal University of São Paulo (Unifesp), focusing on English teacher education, part of the program in which we are involved. We begin by presenting an overview of the program and some of its theoretical underpinnings. We then comment on the courses that deal specifically with the English language and literatures and, following, focus on the English language teacher-education courses. We finally analyze students' report excerpts, verifying what they reveal about the merging of local and global.
\end{abstract}

KEY-WORDS: Teacher Education; English Teachers; Global knowledge; Local Knowledge 


\section{Introdução}

Referindo-se à formação contínua de professores de inglês, Celani (2016) aponta a necessidade de se atingir uma conjunção entre o conhecimento local globalizado e o conhecimento global localizado, conjunção essa a que Kumaravadivelu (2006) se refere como "glocal". Também vislumbramos um percurso formativo para nossos alunos - em sua maioria da Licenciatura em Letras - que considere essa ideia. Assim, o presente trabalho visa a apresentar alguns aspectos do curso de licenciatura em português e inglês da Universidade Federal de São Paulo (Unifesp), mais especificamente a formação de professores de inglês - área do curso em que atuamos -, com o foco no mencionado conceito de glocal (local e global), em um contexto em que consideramos essencial levarse em conta as necessidades e conhecimentos das escolas com as quais trabalhamos (e nas quais nossos alunos realizam seus estágios) durante o processo de formação de futuros professores de língua.

Em nossa proposta de formação inicial de professores, o vínculo entre a universidade e a escola ocupa lugar central, visto que a integração e a colaboração efetivas entre essas duas instituições constituem-se em desafios que buscamos vencer no dia a dia, apoiadas na percepção de que prática, teoria, reflexão e pesquisa precisam andar juntas. Vencer tais desafios torna-se possível de fato apenas quando indivíduos e instituições saem de suas zonas de conforto. Nesse sentido, o Projeto Escola-Universidade em Parceria: A Formação do Professor, discutido mais adiante neste trabalho, é um projeto idealizado e implementado pelo Departamento de Letras no qual a universidade claramente sai de sua zona de conforto para apoiar-se no conceito de glocal.

Em nosso olhar para o local, ressaltamos a atenção que entendemos ser necessária às particularidades das escolas com as quais trabalhamos e da região onde essas escolas e nosso campus se situam, na periferia da cidade de Guarulhos, marcados por infraestrutura precária, problemas sociais e econômicos e frequentes ameaças à segurança. Merecem também atenção os atores que atuam nesse contexto, com seus perfis, potencialidades, necessidades e interesses específicos.

Já em nosso olhar para o global é importante citar o curso em si dada a natureza científico-acadêmica de cursos universitários, ainda que esses se preocupem com o contexto em que estão inseridos. O curso aqui descrito, com duração de cinco anos, engloba oito categorias de Unidades Curriculares (UC) ${ }^{2}$ em sua composição curricular, além das atividades acadêmico-científico-culturais extraclasse obrigatórias, conforme se

\footnotetext{
${ }^{1}$ Os conceitos de local, global e glocal serão discutidos mais adiante.

${ }^{2}$ Trata-se da nomenclatura adotada na Universidade para nos referirmos a disciplinas.
} 
observa no Quadro 1. Cada uma dessas categorias oferece uma gama de UC obrigatórias e/ou eletivas, oferecidas no próprio Departamento de Letras ou em outros departamentos do campus, visando a proporcionar flexibilização e interdisciplinaridade. As UC, por sua vez, envolvem atividades práticas e teóricas em conformidade com aspectos da formação docente.

\begin{tabular}{|l|}
\hline \multicolumn{1}{|c|}{ Categorias de UC } \\
\hline Unidades Curriculares de Formação Básica (UCFB) \\
\hline Unidades Curriculares de Formação Específica (UCFE) \\
\hline Unidades Curriculares de Formação Específica em Licenciatura (UCFEL) \\
\hline Unidades Curriculares de Complementação de Formação (UCCF): \\
\hline Unidades Curriculares de Livre Escolha (UCLE): \\
\hline Unidades Curriculares de Formação de Professor (UCFP) \\
\hline Unidades Curriculares de Domínio Conexo (UCDC) \\
\hline Unidades Curriculares Optativas (UCO): \\
\hline Atividades Científico-Culturais \\
\hline
\end{tabular}

Quadro 1: tipos de UC oferecidas

Por tratar de formação inicial de professores de inglês, neste artigo, enfocamos, prioritariamente, as UC de formação de professores de língua inglesa, da categoria Unidades Curriculares de Formação Específica em Licenciatura (UCFEL), que inclui os estágios supervisionados, embora apresentemos também uma ideia geral das UCFE (Unidades Curriculares Formação Específica (UCFE), no caso, língua inglesa e literaturas de língua inglesa.

Assim, na próxima seção, discutimos alguns conceitos que embasam este artigo; em seguida, visando à contextualização e compreensão das UC enfocadas no trabalho, apresentamos como foram concebidas as UC de língua e literaturas inglesas para, então, tratarmos das UC didático-pedagógicas dedicadas ao ensino da língua inglesa, da categoria UCFEL, as parcerias entre a Universidade e as Escolas de Ensino Básico nas quais são desenvolvidos os estágios supervisionados, mostrando o caminho trilhado para a articulação entre o local e global.

\section{Conceitos e embates}


Ao refletir sobre seu contexto de atuação em programa de formação contínua de professores de inglês, de forma muito pertinente, Celani (2016) discorre sobre o processo de globalização e suas consequências no ensino de línguas, na formação docente, na escola pública e na Linguística Aplicada em geral. Lembra-nos que o fim do século XIX e início do século XX, o projeto modernista levou a uma busca pela homogeneização e eficiência, promovida por países colonizadores, e a um consequente grave apagamento de saberes e experiências em contextos diversos.

No cenário de ensino da língua inglesa, essa situação se fez presente por meio da adoção de teorias, métodos e materiais didáticos produzidos por especialistas, de países dominantes. Canagarajah (1999) ilustra tal situação de forma elucidativa quando descreve uma sala de aula em Sri Lanka onde a professora insiste em reproduzir um modelo importado de ensino de forma completamente indiferente ao que ocorre no local e entre os alunos, imersos em um ambiente de conflitos, próprio da guerra civil que vivenciam. A leitura dedicada e cuidadosa de um texto a respeito do cotidiano de um estudante inglês, feita em voz alta pela professora, encontra apatia, devaneio e falta de interesse por parte de seus alunos. Mais preocupantes que os resultados imediatos de tal orientação em sala de aula são as consequências, a médio e longo prazo, do apagamento das identidades e potencialidades locais e da perda de oportunidades para conscientização e engajamento crítico a respeito da realidade em que vivem os aprendizes. Em contextos muito variados, incluindo as escolas brasileiras, práticas e reações semelhantes vêm se repetindo no mundo todo.

Celani (2016) prossegue em sua exposição, ressaltando que o pós-modernismo procura uma apropriação das diferenças, uma incorporação do saber local de acordo com suas próprias regras, algo que entende como um grande desafio. Questiona como pode, em sua atuação como coordenadora de programa de formação docente, contribuir para que os professores em serviço estejam familiarizados com as teorias prestigiadas na comunidade profissional e, ao mesmo tempo, levem em conta seus perfis, suas experiências, os perfis e as experiências de seus alunos e conduzam práticas pedagógicas que sejam relevantes aos aprendizes. Da mesma forma, mas atuando em programa de formação inicial de professores, debruçamo-nos sobre tal questionamento. Como aliar a teoria à prática sem que a primeira tenha que prover a receita para a segunda?

Interpretamos o termo saber local em sintonia com Celani (2016, p. 550) que, baseada em Canagarajah (2005), define-o como "crenças que não se coadunam com os paradigmas estabelecidos e continuam a circular extraoficialmente em nível local, entre grupos menores". No caso específico de ensino de línguas, conforme ambos os autores, trata-se de saberes desenvolvidos na experiência profissional que não são reconhecidos ou recomendados por especialistas ou autoridades na área. Para a autora, "localidade é um discurso em um contexto e só pode ser definido em relação ao global. É múltiplo e diversificado, tem um caráter dinâmico" (Celani, op. cit, p. 551). Concordamos que a 
adoção de tal conceito pode contribuir para a valorização do saber local, para uma prática profissional crítica e informada e, consequentemente, para o empoderamento do futuro docente.

Como já mencionamos na introdução deste trabalho, Kumaravadivelu (2006) adota o termo glocal para se referir ao resultado dessa construção e reconstrução contínuas de conceitos que integram o local e o global. Trata-se, para ele, do local modificado para acomodar o global e o global modificado para acomodar o local. Embora alguns possam crer que conhecimento global, no nosso caso, constituído de teorias, métodos, abordagens e técnicas de ensino de línguas legitimados, seja veiculado prioritariamente na universidade e que conhecimento local, constituído das experiências dos educadores, seja próprio da escola, devido cuidado é necessário para que tal formulação não seja dicotômica, para que seja compreendida como uma interação recíproca e dinâmica de forma que fique clara a co-construção e não a dualidade que faz com que ora prevaleça o local, ora o global. Ao contrário, é importante que a integração seja construída de forma colaborativa, com negociações e não de forma hierárquica, ou com uma origem específica e quase sempre unilateral. Em outras palavras, é importante que a integração seja uma construção glocal. Esse é o nosso real desafio.

\section{Formação inicial em língua e literaturas de língua inglesa}

Como já mencionado, para melhor compreensão deste trabalho, descrevemos inicialmente o núcleo de formação específica do curso de licenciatura em Letras português-inglês (UCFE). Esse é composto de cinco UC obrigatórias de Língua Inglesa e uma eletiva; temos ainda três UC obrigatórias de Literaturas de Língua Inglesa e uma eletiva.

Ao conceber as UC de Língua Inglesa, o corpo docente do Departamento de Letras levou em conta que um curso superior visando à formação de professores da língua não deve priorizar somente o desenvolvimento das quatro habilidades comunicativas na língua inglesa. Por outro lado, estávamos conscientes de que grande parte de nossos alunos não é proficiente na língua e não tínhamos a intenção de excluí-los. Assim, optamos por atribuir à Língua Inglesa I um caráter introdutório para todos os alunos, independentemente de seus níveis de competência na língua. Como isso foi possível? A UC voltou-se para a leitura de textos que tratam de assuntos de interesse na área, com temas como: as definições de língua e linguagem, o conceito de gênero textual ou discursivo, as funções da língua, as relações entre língua e cultura, as relações entre linguagem e pensamento, a história da língua inglesa, o status da língua inglesa no mundo atual, entre outros. Ao mesmo tempo em que tais temas são estudados, buscamos estimular as reflexões sobre o processo de leitura e levar a uma conscientização sobre o emprego de estratégias. Os textos são todos em inglês, mas há espaço para o uso do português nas discussões, sempre que se considera que essa língua contribui para esclarecimentos, para um aprofundamento mais crítico das questões estudadas ou para o 
desenvolvimento da autoconfiança, a depender da fluência dos alunos. Além disso, o programa de monitoria, da Pró-Reitoria de Assuntos Estudantis, oferece apoio para o que cada professor julgar necessário em sua sala de aula e em sua UC. No caso da monitoria em língua inglesa, o apoio é oferecido àqueles que encontram dificuldades para acompanhar a turma, com atendimento em diversos horários durante a semana, assim como elaboração de materiais de apoio e apresentação de oficinas no Laboratório Interdisciplinar de Formação de Educadores, coordenado pela Profa. Dra. Terezinha Maria Sprenger e do qual as demais autoras deste texto fazem ou já fizeram parte. Entendemos que essas ações, desenvolvidas pelos monitores sob supervisão, levam em conta as diversidades no que concerne à proficiência na língua estrangeira, buscam atender às necessidades individuais e estimulam a colaboração entre os discentes.

Fundamentados em uma concepção social da linguagem e no conceito de gêneros (BAKHTIN, 1953/2003; BAZERMAN; BONINI; FIGUEIREDO, 2009; MARTIN, 1984), organizamos as outras cinco UC de Língua Inglesa de acordo com as situações de uso da língua que consideramos relevantes para a formação acadêmica: o contexto cotidiano, privilegiando os gêneros orais; o contexto das comunicações, enfocando gêneros escritos e orais; e o contexto acadêmico, também enfocando gêneros escritos e orais. Ao mesmo tempo em que trabalhamos em direção ao desenvolvimento de habilidades para a recepção e produção dos gêneros estudados, promovemos leituras e discussões sobre as habilidades comunicativas, sobre perspectivas e conceitos teóricos importantes nas áreas de Linguística e Linguística Aplicada, além de estimular as reflexões a respeito do processo de aprendizagem em que se encontram os estudantes. Discutimos sempre questões de gênero, como já ressaltado, usando os próprios textos adotados nas UC, ora como exemplos de diferentes gêneros, ora como discussão teórica do que seria um trabalho embasado em gêneros.

Assim como acontece em Língua Inglesa, o primeiro semestre de estudos de Literaturas de Língua Inglesa tem um caráter introdutório, visando a revelar um panorama histórico, filosófico, político, cultural e social no qual se inserem as literaturas de língua inglesa. Estuda-se uma seleção da produção literária em língua inglesa em gêneros literários diversos (poesia, conto, romance e seus subgêneros) e de diversas épocas, desde seus primórdios até o pós-colonialismo. As três demais UC de literatura - uma das quais é oferecida como eletiva - abordam os gêneros poéticos, narrativos e as obras compostas para o teatro, a partir de uma perspectiva crítica e teórica que situa as produções literárias em seus diversos contextos histórico e socioculturais - o que implica o estudo de produções de diferentes países de língua inglesa.

Tendo descrito brevemente o contexto geral do curso e as disciplinas de Língua Inglesa e Literaturas de Língua Inglesa, passamos a discorrer sobre a dimensão que se volta mais especificamente para a formação inicial do(a) educador(a) para o ensino da língua inglesa. Vale ressaltar mais uma vez que, ao pensarmos a formação docente em um contexto de uma universidade pública, de certa forma privilegiada, cercada de escolas e comunidades com baixo poder aquisitivo, como é o caso do nosso entorno, lidamos com 
forças que precisam ser pensadas para (1) formar o aluno para atuar no contexto em que esse muitas vezes vive e no qual gostaria de fazer alguma diferença; (2) abrir espaço para que a escola seja respeitada e valorizada, em que sua voz seja ouvida, em que os professores sejam, em última instância, parceiros da produção de conhecimento. No entanto, não podemos esquecer do papel que a universidade geralmente exerce nas comunidades escolares, nem em como a universidade é vista pelos educadores - como produtora de conhecimento científico pouco aplicável na prática. Decidimos discutir essa questão pelos conceitos de local, global e glocal, conforme expostos na seção anterior, precisamente por causa dessas forças e de como um curso pode responder a elas.

\section{Formação inicial do educador para o ensino da língua inglesa: do global para o local e vice-versa}

As UC didático-pedagógicas obrigatórias dedicadas ao ensino da língua inglesa são: Fundamentos do Ensino de Língua Inglesa I e II, acompanhadas dos respectivas práticas pedagógicas: Estágio Curricular Supervisionado em Inglês I e II. Juntas, elas fazem parte da categoria UCFEL ${ }^{3}$. Essas UC são oferecidas em dois semestres letivos e acontecem concomitantemente, i.e.: Fundamentos I com Estágio I e Fundamentos II com Estágio II. Relacionadas ao ensino de língua e literatura portuguesas, na mesma categoria de UC obrigatórias, temos: Língua, Literatura e Ensino: Fundamentos I; Língua, Literatura e Ensino: Fundamentos II e respectivos estágios I e II, comuns aos quatro cursos de Licenciatura da instituição $0^{4}$. Constam ainda da mesma categoria outras UC obrigatórias e comuns aos quatro cursos, relacionadas ao ensino, a saber: Práticas de Formação Docente, com conhecimentos mais gerais sobre os fundamentos de ensino, questões legais, etc. e Língua Brasileira de Sinais, ministrada por professores surdos e/ou com grande conhecimento, experiência e pesquisa na área.

Além de cursar as UC obrigatórias, nossos alunos precisam escolher ao menos três UC de suas preferências dentro de um conjunto de UC de formação de professor (UCFP), tais como Ensino/aprendizagem da Leitura em Língua Estrangeira: aspectos teóricos e metodológicos; Formação Docente, Ensino de Línguas e o Uso das Tecnologias Digitais de Informação e Comunicação; Formação Docente para o Trabalho com Necessidades Educacionais Específicas e/ou para Inclusão, a qual trataremos adiante, entre outras.

\footnotetext{
${ }^{3}$ Ver quadro 1.

4 A Unifesp oferece quatro cursos de licenciatura: Português, Português-Espanhol, PortuguêsFrancês e Português-Inglês. Neste trabalho enfocamos o curso de Português-Inglês.
} 
Descrevemos a seguir as UC Fundamentos do Ensino de Língua Inglesa I e II e Estágios Supervisionados correspondentes por serem mais específicas para o tema deste artigo já que se relacionam exclusivamente ao ensino da língua inglesa.

As UC de Fundamentos possuem carga horária de 60 horas cada, divididas em prática (50\%) e teórica (50\%). Já as UC denominadas Estágio Curricular Supervisionado em Inglês I e II possuem carga horária diferenciada, a primeira com 70 horas e a segunda com 65 .

A UC Fundamentos I tem por objetivos apresentar as teorias de ensinoaprendizagem (comportamentalismo, humanismo, cognitivismo, teoria sócio-históricocultural) e de linguagem (visões estruturalista, funcional e prática social) que subjazem aos métodos e abordagens de ensino de língua inglesa, bem como o estudo de tais métodos e abordagens para que os alunos possam fazer reflexões críticas acerca das escolhas realizadas em cada situação educacional. Também se busca a compreensão e reflexão por meio de leitura crítica dos seguintes documentos oficiais: PCN-LE (BRASIL, 1998); PCN-EM e PCN+ (BRASIL, 2000,2002); Orientações Curriculares para o Ensino Médio (BRASIL, 2006); Currículo do Estado de São Paulo (SÃO PAULO, 2011) e BNCC (BRASIL 2017). Como o curso não oferece nenhuma UC obrigatória dedicada exclusivamente a questões de tecnologias digitais e ensino de inglês, decidimos, mais recentemente, oferecer como parte dos conteúdos trabalhados questões que se referem a novas teorias de aprendizagem que trazem em seu bojo o desenvolvimento humano mediado por tecnologia e pela cultura digital (SIEMMENS, 2005; ELLIS; LARSENFREEMAN, 2009) e as possibilidades da tecnologia digital (DUDENEY; HOCKLY, 2012; TOMLINSON; WHITTAKER, 2013; FLORES, 2015; entre outros) a fim de manter um diálogo com as novas tendências educacionais e as diversas possibilidades de recursos e ambientações que o mundo digital hoje oferece ao ser humano em sociedade e, em especial, à educação. Aproveitamos também para debater essas questões, que hoje se fazem presentes nos novos documentos oficiais, frente às observações de aula feitas pelos alunos e como essas questões se materializam nas escolas públicas observadas. Esse é hoje um diferencial de nosso curso de formação, quando comparado a outros vigentes no país que ainda não tratam, ou pouco tratam, desses temas em seus conteúdos programáticos.

Já na UC Fundamentos II, tomamos por base os documentos oficiais e as questões teórico-metodológicas estudadas anteriormente a fim de fomentar uma reflexão crítica para análise, avaliação, adaptação e produção de propostas didático-pedagógicas relativas ao ensino da língua inglesa para o contexto de ensino-aprendizagem atual, buscando criar um espaço para que o aluno se familiarize com o mercado de trabalho existente - ensinoaprendizagem de inglês para crianças, adolescentes, EJA e pessoas com deficiência ou necessidades específicas. Em especial, buscamos criar um lócus para que o aluno possa realizar estudos críticos sobre o Ensino Fundamental e Médio da escola pública, aliando a teoria às questões práticas observadas durante o estágio supervisionado. 
Ressaltamos que a escolha de conteúdos também traz outro componente que nem sempre é encontrado em disciplinas dedicadas à formação inicial do professor, a saber: ensino-aprendizagem de inglês para pessoas deficientes ou com necessidades específicas, cada vez mais necessário à formação inicial do professor devido às novas propostas globais e aos contextos e conhecimentos locais, temática que pode ser expandida e melhor trabalhada na UC Formação Docente para o Trabalho com Necessidades Educacionais Específicas e/ou para Inclusão, apresentada adiante.

É parte também das escolhas que fazemos para essas UC que o material teórico que as embasa possa oferecer aos alunos a vivência da diversidade multimodal de textos, contando, portanto, com fontes impressas e audiovisuais, apresentando explicações teóricas, autores e suas tendências, bem como vídeo-aulas que exemplificam diferentes métodos e abordagens de ensino e aprendizagem.

Importante salientar ainda que tanto Fundamentos I como II estão embasadas nos princípios de formação crítico-reflexiva (SCHÖN, 1983, [1987]/2000, ZEICHNER; LISTON, 1987; PIMENTA, 2002; ALARCÃO, 2011; CELANI, 2004) além do conceito de glocal (KUMARAVADIVELU, 2006) como já explicitado, porquanto as duas unidades curriculares não só objetivam formar alunos críticos, no que diz respeito a conteúdos voltados ao ensino-aprendizagem, mas também criar um lócus para que os alunos possam refletir sobre os requisitos necessários para seus Estágios Curriculares Supervisionados em Inglês I e II. As atividades em que são discutidas as teorias, os documentos oficiais e todo o conteúdo, incluindo, como já falamos, as novas tecnologias são fomentadas por debates, pesquisas e seminários seguidos de discussões em sala, bem como apresentações e discussões sobre as observações de aula feitas durante as UC Estágio Supervisionado.

Fora essas questões de ordem mais teórico-práticas, promovemos também uma reflexão crítica acerca de questões geopolíticas do ensino de línguas (Para quê ensinar inglês em escolas regulares públicas e privadas? O quê ensinar de língua inglesa nesses espaços?), importante para que o futuro profissional possa melhor entender sua atuação profissional e seu papel no sistema sócio-político-educacional.

Quando o aluno inicia o Estágio Supervisionado, já terá realizado várias reflexões acerca do papel do inglês na sociedade brasileira - e mais especificamente, na local, ou seja, em Guarulhos -, assim como terá estudado diversas teorias, metodologias de ensino de língua e pensado, juntamente com seus colegas e professoras, o que vai buscar na escola.

Na concepção das UC Estágio Curricular Supervisionado em Inglês I e II de nosso curso, partimos do pressuposto de que universidade e escola precisam, mais do que estar em sintonia, ser parceiras em processos construídos mutuamente e compartilhados por todos os atores envolvidos, principalmente, professores-supervisores de estágio, licenciandos, diretores, coordenadores e professores de inglês, orientadores do estágio na escola. 
A fim de poder operacionalizar esse princípio, elaboramos, em 2011, em conjunto com os outros cursos de Letras da Unifesp, o Projeto Escola-Universidade em Parceria: A Formação do Professor.

Esse projeto foi apresentado à comunidade no "I Encontro Escola Universidade em Parceria: a Formação do Professor de Línguas e Literatura" no nosso campus no final do ano de 2011. Esse encontro foi seguido por visitas às escolas que aceitaram o convite para participar e, a partir daí, foram estabelecidas parcerias entre os cursos de Letras da Unifesp, cinco escolas estaduais do município de Guarulhos e uma escola municipal em São Paulo, localizada nas proximidades de uma estação do metrô, para facilitar o acesso aos licenciandos que trabalham e/ou residem em São Paulo e têm dificuldades para realizar o estágio em Guarulhos, principalmente os do curso noturno.

As escolas públicas parceiras de ensino básico são, portanto, o lócus prioritário desse processo de estágio. No entanto, são ainda oferecidas aos alunos experiências em diferentes ambientes educacionais. Estabelecemos parceria com uma escola bilíngue, em São Paulo, e com um instituto de idiomas, em Guarulhos, onde os alunos são incentivados a realizar algumas horas de estágio como forma de entenderem melhor o mercado de trabalho e as diferentes metodologias e teorias que as embasam ${ }^{5}$.

Destacamos que é concomitantemente à UC Fundamentos II que os alunos fazem o Estágio de regência e, consequentemente, devem colocar em prática conhecimentos teórico-metodológicos aprendidos, desta vez de forma mais concreta do que em Fundamentos I, para pensar nas necessidades da(s) escola(s) em que faz(em) estágio e suas respectivas turmas. Nesse sentido, Fundamentos e Estágio lançam um olhar para a dialogicidade entre local e global. Alguns dos excertos abaixo ilustram o olhar para o local e o refletir de modo a juntar esse conhecimento àquele que deriva do global de modo a transformá-lo em glocal:

Um aspecto chamou-me muita atenção durante as observações de aula (...) foi o uso excessivo do celular por parte dos alunos. Na maioria das vezes eles estavam escutando música, jogando ou ainda acessando o facebook. Tendo em vista o leque de possibilidades no uso das novas tecnologias, questionei-me muito sobre o que seria possível fazer com a integração dessas tecnologias e mais, dos recursos virtuais, como o facebook para a aprendizagem de língua estrangeira.

5 Como forma de exemplificar, vale dizer que os alunos geralmente voltam da escola bilíngue ou do curso de idiomas dizendo que, finalmente, entenderam a teoria $\mathrm{X}$ ou o método ou abordagem de ensino de idiomas Y. Por esse motivo, incentivamos que esses estágios, embora com um número menor de horas, sejam realizados por eles. No entanto, eles podem optar por realizar o estágio apenas na escola pública. 
Depois de mencionar leitura de um texto sobre tecnologia feito na UC de Fundamentos, o aluno complementa sua observação com a seguinte reflexão:

(...) é possível a utilização desse recurso virtual como uma forma de estreitar relações entre os alunos, assim como possibilitar uma maior interação entre o grupo. Ainda que isso seja um pouco utópico, sobretudo quando consideramos as turmas superlotadas, esse meio permitiria fazer uso da língua-alvo em um ambiente real, dada as possibilidades de interação que são permitidas nas redes sociais (JOÃO $\left.{ }^{6}, 2017\right)$.

Como é possível perceber, o aluno faz uma reflexão sobre o trabalho realizado na UC de Fundamentos e na observação da sala de aula de ensino básico. João compreende que seria ideal trabalhar com tecnologia apesar da diversidade e das barreiras do contexto local. Tal diversidade também é percebida por Fernando, quando percebe a heterogeneidade de uma sala de aula:

Nesse dia, mais especificamente, ative-me à observação dos alunos, no modo como se comportavam e como era a relação com os demais colegas de classe. Com isso, pude ver quão heterogênea é uma sala de aula, dado que cada aluno contribui para a criação da identidade daquela turma em específico. Pude ver, por exemplo, que cada aluno se comporta de um modo diferente diante da figura de um estranho, no caso, eu (FERNANDO, 2017).

No entanto, essa heterogeneidade não desmotiva o aluno. Ao contrário, o faz refletir sobre as necessidades específicas de cada sala de aula e de cada aluno. Em outras palavras, o faz refletir sobre as necessidades locais.

Com a observação em outras duas salas de nono ano, pude ver que as classes são muito heterogêneas e que, por isso, deve-se respeitar a individualidade das turmas, já que cada uma terá um ritmo diferente para se ensinar, bem como necessitará de uma atenção diferenciada, dada a dificuldade que possam apresentar nessa aprendizagem.

Vale lembrar que os alunos, colocando-se nos papeis dos professores que estão observando, conseguem, talvez devido às leituras e reflexões que fazem, perceber as dificuldades que os professores das escolas públicas têm, como é o caso do excerto do relatório de Wagner:

\footnotetext{
${ }^{6}$ Nomes fictícios.
} 
Os professores estão sempre desmotivados, desanimados e cansados, pois trabalham mais de dez horas por dia. Na sala dos professores, pergunto se eles têm horários para planejamento de aulas ou atividades no período em que estão na escola, e eles me explicam que se tiverem vinte aulas por semana naquela escola, terão dois horários de ATPC (Aula de Trabalho Pedagógico Coletivo), e se tiverem 30 aulas por semana, terão três horários de ATPC, mais algumas poucas horas para planejamento, reuniões etc. Como é sabido, ao menos $50 \%$ do tempo de trabalho dos professores deveria ser cumprido fora da sala de aula, para que pudessem se dedicar com qualidade a estas atividades pedagógicas, mas a realidade das escolas públicas estaduais de São Paulo está longe de ser ao menos razoável (WAGNER, 2017).

Ao mesmo tempo, percebem o esforço de professores que tentam, apesar de suas limitações e dificuldades, contemplar questões trazidas pelos alunos e promover uma discussão crítica sobre assuntos relativos à cidadania. É o demonstra o trecho do relatório de Ana:

A professora Helena segue as orientações de conteúdo apresentadas no Currículo do Estado de São Paulo de 2011, como, por exemplo, usa biografias de pessoas marcantes, como Gandhi, a jogadora Marta (...). Gostei bastante quando ela tentava responder às perguntas dos alunos, mesmo que estivessem fora do texto e por vezes fugissem um pouco do assunto principal, levando em consideração a curiosidade e o interesse dos alunos, enxergando-os, desta forma como pessoas inteiras, assim como pode ser visto na psicologia humanística de Rogers(...). A professora Helena também demonstrou um senso crítico muito significativo quando discutiu com os alunos sobre a posição das mulheres em sociedade, sobre a realidade da própria escola e do país durante as aulas (ANA, 2017).

Reconhecemos que a universidade, muitas vezes, assume um papel de transmissora de conhecimento que, no caso de língua inglesa, é ainda mais evidentemente um conhecimento global e isso se faz reproduzir na sala de aula pelos conteúdos prescritos (currículo do Estado). No entanto, como demonstra o excerto, a professora Helena aproveita a oportunidade trazida pelas perguntas dos alunos para deixar o espaço de poder que é evidentemente mais global para aproximar-se dos interesses dos alunos (mais evidentemente locais), chegando a uma discussão crítica que consideramos uma aproximação do glocal.

No entanto, não são todos os alunos que buscam o glocal. Alguns fazem a leitura do local, comparando-o com o global que idealizam porque o aprenderam na universidade. São comuns os casos de relatórios em que os alunos listam atividades 
realizadas pelos professores da escola pública apenas para classificá-las como o método $\mathrm{x}$ ou $\mathrm{y}$, considerado melhor ou pior de acordo com a sua compreensão do que foi estudado na universidade. No exemplo a seguir, Danusa (2017) demonstra considerar que para se trabalhar com compreensão oral em sala de aula, o professor precisa seguir uma regra de três estágios:

O exercício consistia em uma música do Jason Mraz, 93 Million Miles, e eles precisavam completar as lacunas de palavras que envolviam o clima enquanto ouviam a música. Esse exercício foi passado em todas as aulas dela do ensino fundamental. Diferente do que vimos no texto Methodology in Language Teaching, de Richards e Renandya, a professora trabalhou apenas com o listening, enquanto o que poderia ser feito era um trabalho de pré e pós listening, como podemos ver no quadro abaixo, para que o assunto da aula ficasse mais completo.

Pre-listening

Set context. Create motivation.

Listening

Extensive listening (followed by questions on context, attitude)

Preset task/Preset questions

Intensive listening

Checking answers

Post-listening

Examining functional language

Inferring vocabulary meaning

Esta seção descreveu algumas das UC de Formação Específica em Licenciatura, ilustrando, por meio dessas descrições e da análise dos excertos de relatórios dos alunos como o global e o local podem se encontrar seja no trabalho proposto - como na parceria Universidade-Escola -, seja na compreensão que dele fazem os alunos-estagiários.

\section{7. À Guisa de Considerações Finais}

Fizemos, aqui, um resumo das práticas de formação do curso integrado de Licenciatura em Letras Português-Inglês da Unifesp, com algumas das considerações teóricas que embasam a nossa prática. Evidentemente, devido às restrições de espaço 
pelo qual precisamos nos pautar, focamos, prioritariamente, os princípios teóricos de local, global e glocal. Demos prioridade, como é próprio de trabalhos que se organizam sem ter a Academia como centro de todo o processo, à descrição da prática e relatos das ações e organizações, utilizando a teoria apenas para explicá-los.

Consideramos que a formação inicial do educador requer comprometimento por parte da(s) instituição(ões) envolvida(s) para que esse aluno-professor tire o maior proveito possível desse momento. Por outro lado, as escolas estão cansadas de alunos que as utilizam para fazer seus estágios e pesquisas iniciais sem que haja qualquer retorno para o espaço escolar, a formação do professor em-serviço ou a formação do aluno de educação básica. Somos contrárias a essa visão de estágio ou de pesquisa. Acreditamos que o trabalho precisa ser conjunto e transformar, durante o processo de ensinar-aprender, tanto as práticas escolares, como suas teorias e tanto as práticas universitárias, quanto suas teorias. Isso só é possível quando deixamos de ser "nós" e "eles" para sermos "todos nós."

\section{Referências bibliográficas}

ALARCÃO, I. Professores reflexivos em uma escola reflexiva. 8 ed. Coleção questões da nossa época. São Paulo: Cortez, 2011.

BAKHTIN, M. Estética da criação verbal. Tradução de Paulo Bezerra. 4a. ed. São Paulo: Martins Fontes, 1953/2003.

BAZERMAN, C.; BONINI, A.; FIGUEIREDO, D. (Orgs.) Genre in a changing world (Perspective on writing). Fort Collins, Colorado: The WAC Clearinghouse and Parlor Press, 2009.

BRASIL, MEC. Parâmetros Curriculares |Nacionais: Terceiro e quarto ciclos do ensino fundamental: língua estrangeira. Brasília: MEC/SEF, 1998.

BRASIL. MEC. Parâmetros Curriculares Nacionais (Ensino Médio). Linguagens, códigos e suas tecnologias. Brasília: MEC, 2000.

BRASIL, Secretaria de Educação Média e Tecnológica. $P C N+$ ensino médio:

orientações educacionais complementares aos parâmetros curriculares nacionais. Linguagens, códigos e suas tecnologias. Brasília: MEC, SEMTEC, 2002.

BRASIL. MEC. Orientações curriculares para o ensino médio. Volume 1: Linguagem, códigos e suas tecnologias. Brasília: MEC, 2006.

BRASIL, Ministério da Educação. Base Nacional Comum Curricular. Terceira versão. Brasília: MEC, 2017.

CANAGARAJAH, A.S. Resisting linguistic imperialism in English teaching. Oxford: Oxford University Press. 1999.

. Reconstructing local knowledge, reconfiguring language studies. In: CANAGARAJAH, S. (Org.). Reclaiming the local in language policy and practice. Mawhaw, New Jersey: Lawrence Erlbaum Associates, Publishers, 2005. CELANI, M.A.A. Um desafio na linguística aplicada contemporânea: a construção de saberes locais. D.E.L.T.A., vol.32, no 2, p. 543-555, 2016.

Culturas de aprendizagem: risco, incerteza e educação. In:

DUDENEY, G. ; HOCKLY, N. ICT in ELT: how did we get here and where are we 
The ESPecialist: Descrição, Ensino e Aprendizagem, Vol.39 No.1 jan-jul 2018 https://revistas.pucsp.br/esp CThe ESPecialist

ISSN 2318-7115

going? ELT Journal, vol. 66, no 4, p. 533-542, 2012. Disponível em https://doi.org/10.1093/elt/ccs050. Acesso em 8 fev de 2018.

ELLIS, N.C.; LARSEN-FREEMAN, D. (Orgs.) Language as a Complex Adaptive System. Language Learning, n. 59, Sup. 1, Dezembro 2009.

FLORES, J. F. F. Using gamification to enhance second language learning. Digital Education Review, no 27, Junho 2015. Disponível em http://greav.ub.edu/der/. Acesso em 08 fev. 2018.

GIROUX, H.A. Os professores como intelectuais: rumo a uma pedagogia crítica da aprendizagem. Porto Alegre: Artmed. 1997.

KUMARAVADIVELU, B. A linguística aplicada na era da globalização. In: MOITA LOPES, L. P. (org.). Por uma linguística aplicada INdisciplinar. São Paulo: Parábola Editorial, 2006.

MARTIN. J. R. Language, register and genre. In CHRISTIE, F. (Org.) Children Writing: A Reader. Vic.: Deakin University Press, p. 21-29, 1984.

PIMENTA, S. G. Professor reflexivo: construindo uma crítica. In: PIMENTA, S.G.; GHEDIN, E. (orgs.). Professor reflexivo no Brasil: gênese e crítica de um conceito. . $2^{\mathrm{a}}$ ed.São Paulo: Cortez, 2002, p.17-52.

SÃO PAULO. Secretaria de Educação. Currículo do estado de São Paulo. Linguagens, códigos e suas tecnologias. São Paulo: Secretaria de Educação. 2a. ed. 2011.

SCHÖN, D. The reflective practitioner: how professionals think in action. U.S.A.: Basic Books, Inc., 1983.

. Educando o profissional reflexivo: um novo design para o ensino e a aprendizagem. Trad. Roberto Cataldo Costa, Porto Alegre: Artes Médicas Sul, $1987 / 2000$.

SIEMMENS, G. Connectivism: A learning theory for the digital age. International Journal of Instructional Technology and Distance Learning, vol. 2. no , p.3-10, 2005. TOMLINSON, B. ;WHITTAKER, C. (Orgs.) Blended learning in English language teaching: Course design and implementation. London: British Council, 2013. ZEICHNER, K.M. \& LISTON, D. P. Teaching student teachers to reflect. Harvard

Rosinda de Castro Guerra Ramos holds a PhD in Applied Linguistics from PUC-SP. She was a former professor at the Post-Graduate Program in Applied Linguistics and Language Studies at PUC-SP and a visiting professor at the English Department at Unifesp. Her interests are English Language teaching, Language for Specific Purposes, Teacher Education, Materials Writing, Autonomy and ICTi in Education. rramos1@uol.com.br

Sueli Salles Fidalgo is a professor, currently also the coordinator, of the Teaching Programme in Portuguese and English, and a professor at the Postgraduate Programme in Education and Health, where she supervises academic investigations focusing on teacher education, ex/inclusive education and/or specific educational needs. She holds a PhD in Applied Linguistics and Language Studies from PUC-SP.ssfidalgo@terra.com.br 
Terezinha Maria Sprenger holds a PhD in Applied Linguistics from Pontifical Catholic University of São Paulo, Brazil, and is a professor in the English Department, at Federal University of São Paulo. Her research interests include EFL teaching and learning, teacher education, learner and teacher autonomy and the use of ICT in Education.terezinha.sprenger@gmail.com. 